\title{
Treatment effect of TUSPLV on recurrent varicocele
}

\author{
TIAN-ZHONG YAN, XIAO-QIANG WU and ZHI-WEI WANG \\ Department of Urology, Henan Provincial People's Hospital, Zhengzhou, Henan 450003, P.R. China
}

Received April 21, 2016; Accepted September 2, 2016

DOI: $10.3892 /$ etm.2016.3931

\begin{abstract}
The aim of the study was to analyze the treatment effect of transumbilical single-port laparoscopic varicocelectomy (TUSPLV) on recurrent varicocele (VC). In order to compare the surgical effects of TUSPLV to traditional retroperitoneal ligation of the internal spermatic vein, 64 patients with recurrent $\mathrm{VC}$ were enrolled and divided into the control group $(n=30)$ and the observation group $(n=34)$. Patients in the control group underwent surgery using traditional retroperitoneal ligation of the internal spermatic vein, while those in the observation group underwent surgery using TUSPLV. The results showed that the time of operation and bleeding volume in the observation group were significantly lower. The occurrence and recurrence rates of periprocedural complications were considerably lower in the observation group. Differences were statistically significant $(\mathrm{P}<0.05)$. In terms of the pregnancy rate, the difference between the 2 groups had no statistical significance $(\mathrm{P}>0.05)$. We concluded that employing TUSPLV to treat recurrent VC was safe and effective.
\end{abstract}

\section{Introduction}

Varicocele (VC) is responsible for $\sim 30-40 \%$ of primary male infertility. It can be divided into the adult type and juvenile type, and often occurs in the left side of testis (rate, 77-92\%) (1). Several causes have been identified for this disease including absence or dysfunction of spermatic vein valve, weakness of vein wall and connective tissues around the vein wall, cremaster hypoplasia and spermatic vein return resulting from erect posture (2). The traditional operation, laparoscopy and microtechnique are the main treatment methods used for patients. However, the postoperative recurrence rate is relatively high (20-30\%) (3). Postoperative recurrence can seriously reduce the patient's quality of life and adds difficulty to the second operation (4).

Correspondence to: Dr Tian-Zhong Yan, Department of Urology, Henan Provincial People's Hospital, 7 Weiwu Road, Zhengzhou, Henan 450003, P.R. China

E-mail: vhpgcrbty60@163.com

Key words: transumbilical single-port laparoscopic varicocelectomy, recurrent varicocele, retroperitoneal ligation
In the present study, the treatment effect of transumbilical single-port laparoscopic varicocelectomy (TUSPLV) on recurrent VC by comparing the surgical effects of TUSPLV with traditional retroperitoneal ligation of the internal spermatic vein was analyzed.

\section{Materials and methods}

Object information. From June, 2013 to January, 2015, a total of 64 patients diagnosed with recurrent VC and having suffered from primary VC were enrolled. Patients with scrotal pain were evaluated by the visual analogue scale (VAS). Color Doppler ultrasound was used to evaluate: i) The varicosity degree (CDFI standard); ii) the volume of testis [the calculation formula was volume $(\mathrm{ml})=$ length $\mathrm{x}$ width $\mathrm{x}$ thickness $(\mathrm{mm}) \times 0.71]$; the testicular atrophy index (AI) [calculation formula was $\mathrm{AI}=$ (the right side - the left side) volume of testis/volume of the right side of testis $\mathrm{x} 100 \%$ ] and $\mathrm{AI}>15 \%$ was considered testicular atrophy; and iii) the routine analysis on the sperm quality including sperm volume, liquefaction time, $\mathrm{pH}$, sperm concentration, morphology and activity ratio.

The present study was approved by the Ethics Committee of the Henan Provincial People's Hospital (Henan, China). Written informed consent was obtained from the patients or their families.

Patients were divided into the control group $(n=30)$ and the observation group $(n=34)$ according to the surgical methods they underwent. Patients in the observation group were treated with TUSPLV and those in the control group were treated with traditional retroperitoneal ligation of the internal spermatic vein. According to the baseline data comparison between the two groups, the differences had no statistical significance $(\mathrm{P}>0.05)$ (Table I).

Surgical method. The control group surgeries were completed according to the standard surgical process and the surgeries in the two groups were completed by the same surgical and nursing team. For the TUSPLV, the single-port and multi-channel cannula were self-made by using two elastic rubber rings and no. 7 gloves (rubber ring with a diameter of $7 \mathrm{~cm}$ was used to cover the glove cuff as an 'outer ring' and the other rubber ring with a diameter of $3 \mathrm{~cm}$ was used to cover the middle part of the glove). The glove was reversed in order that the rubber ring would turn to be the inner ring and then the part of thumb, middle finger and little finger tip on the glove were cut off so that the metal cannula could be placed in the middle finger and the 
Table I. Baseline data comparison between two groups.

\begin{tabular}{|c|c|c|c|c|c|c|c|c|c|c|c|c|}
\hline Groups & $\begin{array}{l}\text { No. of } \\
\text { cases }\end{array}$ & $\begin{array}{l}\text { Age } \\
\text { (years) }\end{array}$ & $\begin{array}{l}\text { Left } \\
\text { side }\end{array}$ & Infertility & $\begin{array}{l}\text { Volume } \\
\text { of testis } \\
(\mathrm{ml})\end{array}$ & $\begin{array}{c}\text { Testicular } \\
\text { atrophy }\end{array}$ & $\begin{array}{l}\text { Varicosity } \\
\text { degree II }\end{array}$ & $\begin{array}{l}\text { Varicosity } \\
\text { degree III }\end{array}$ & $\begin{array}{l}\text { No. of } \\
\text { recurrence }\end{array}$ & $\begin{array}{l}\text { Mean time } \\
\text { of recurrence } \\
\text { (months) }\end{array}$ & $\begin{array}{l}\text { Traditional } \\
\text { operation of } \\
\text { the previous } \\
\text { operation } \\
\text { types }\end{array}$ & Laparoscope \\
\hline Control & 30 & $24.5 \pm 5.3$ & $26(86.7)$ & $20(66.7)$ & $14.2 \pm 2.7$ & $17(56.7)$ & 14 & 16 & $1.2 \pm 0.3$ & 8.2 & 16 & 14 \\
\hline Observation & 34 & $24.3 \pm 5.5$ & 27 (79.4) & $22(64.7)$ & $14.5 \pm 2.8$ & $19(55.9)$ & 15 & 19 & $1.3 \pm 0.2$ & 8.4 & 18 & 16 \\
\hline $\mathrm{t}\left(\chi^{2}\right)$ & & 0.632 & 0.589 & 0.027 & 0.726 & 0.004 & 0.042 & 0.934 & 0.124 & & \multicolumn{2}{|c|}{0.001} \\
\hline P-value & & 0.454 & 0.443 & 0.869 & 0.922 & 0.950 & 0.838 & 0.876 & 0.789 & & \multicolumn{2}{|c|}{0.975} \\
\hline
\end{tabular}

other two valve circles placed in the thumb and the little finger. Finally they were tied up and fixed by the suture lines. The incision with length of $2 \mathrm{~cm}$ was made below the umbilicus and the single-port and multi-channel cannula was placed inside the open abdomen. The 'outer ring' was placed in the incision while the 'outer ring' was placed outside of the incision and $\mathrm{CO}_{2}$ was injected through the metal cannula and the glove was pulled at the same time to make the inner ring stick close to the inside of the incision. The outer ring was kept close to the outside of the incision in a way that the sealed incision would not leak and the pneumoperitoneum pressure was maintained at $13 \mathrm{mmHg}$. The scope entered the body through the metal cannula in the part of the middle finger and surgical instruments entered the body through the cannulas in the part of the little finger and the thumb. Through the scope, we started by verifying any possible injuries in the organs. We could see the spermaduct from $\sim 1.5 \mathrm{~cm}$ above the inner ring and observed that the A-shaped spermaduct was running downward. For the patients who suffered from sigmoid colon and peritoneal adhesion on the left side, we released the adhesion and then found the spermatic vessels. Scissors were used to cut the posterior peritoneum located in $\sim 2 \mathrm{~cm}$ above the spermaduct to separate and reveal the internal spermatic veins which generally had 2-3 branches. We distinguished and reserved the testicular artery, dissociated the internal spermatic veins and then coagulated and cut the internal spermatic veins with ligasure vessel sealing system (ligasure ${ }^{\mathrm{TM}}$ ) and checked whether there were other venule branches. We used the same method to deal with the other side of the testis. Subsequently, we reduced the abdominal pressure and removed the pneumoperitoneum as well as cannulas once we were confident that there was no hemorrhage. We then sewed up the skin incision layer by layer (Fig. 1).

Observation target. Patients in the two groups were followed up for $\sim 12$ months to determine the differences regarding the time of operation, bleeding volume during operation, perioperative complications, recurrence rate and pregnancy rate.

Statistical analysis. SPSS 19.0 statistical software (Chicago, IL, USA) was used for data analysis. Quantitative data were represented by the mean \pm standard deviation and the comparison between groups was checked by t-test. Qualitative data were represented by the number of cases or the percentage (\%) and the comparison between groups was verified using $\chi^{2}$ test. $\mathrm{P}<0.05$ was considered to indicate a statistically significant difference.
Table II. Comparison of operative time and bleeding volume during operation.

\begin{tabular}{lcc}
\hline Groups & Operative time (min) & Bleeding volume (ml) \\
\hline Control & $63.5 \pm 10.5$ & $167.8 \pm 24.5$ \\
Observation & $46.2 \pm 7.5$ & $125.4 \pm 21.3$ \\
t-test & 4.628 & 4.795 \\
P-value & 0.041 & 0.039 \\
\hline
\end{tabular}

\section{Results}

Comparison of operative time and bleeding volume during operation. The operative time and bleeding volume in the observation group were reduced significantly and the difference was statistically significant $(\mathrm{P}<0.05)$ (Table II).

Comparison of perioperative complications, recurrence rate and pregnancy rate. The occurrence and recurrence rates of perioperative complications in the observation group reduced significantly. Differences were of statistical significance $(\mathrm{P}<0.05)$. Comparison between the pregnancy rate between groups showed no statistically significant difference $(\mathrm{P}>0.05)$ (Table III).

\section{Discussion}

Complications and recurrence reasons. Hydrocele of tunica vaginalis is the most common complication after the spermatic vein ligation which mainly results from the injury and faulty ligation of lymphatic vessels. The occurrence rate is $3-39 \%$ (5). The occurrence rate of postoperative testicular atrophy is $\sim 0.2 \%$ and it is mainly caused by the ligation or injury of testicular artery (6). The recurrence rate after the spermatic vein ligation usually range from 0.6 to $45 \%$ (7) and the reasons for recurrence mainly include: i) Branches of spermatic vein fail to be ligated completely and some scholars label the VC with collateral vein as aberrantly fed VC (AFV). They believe that the postoperative recurrence mainly results from AFV and missing ligation of lateral vein (8). Currently, the spermatic vein radiography is the most reliable method to diagnose primary VC, among which the selective spermatic vein radiography has the best result (9). ii) Inner spermatic vein fails to be cut after ligation or the inner spermatic vein 
Table III. Comparison of perioperative complications, recurrence rate and pregnancy rate cases, $(\%)$.

\begin{tabular}{|c|c|c|c|c|c|c|c|c|c|}
\hline Groups & $\begin{array}{l}\text { No. of } \\
\text { cases }\end{array}$ & $\begin{array}{l}\text { Hydrocele of } \\
\text { tunica vaginalis }\end{array}$ & $\begin{array}{c}\text { Testicular } \\
\text { artery injury }\end{array}$ & $\begin{array}{l}\text { Injury of organs } \\
\text { and blood vessels } \\
\text { in the pelvic cavity } \\
\text { and abdominal cavity }\end{array}$ & Infection & Others & $\begin{array}{l}\text { Occurrence } \\
\text { rate of } \\
\text { total } \\
\text { complications }\end{array}$ & $\begin{array}{l}\text { Recurrence } \\
\text { rate }\end{array}$ & $\begin{array}{l}\text { Pregnancy } \\
\text { rate }\end{array}$ \\
\hline Control & 30 & 3 & 1 & 3 & 2 & 1 & $10(33.3)$ & $12(40.0)$ & $16(53.3)$ \\
\hline Observation & 34 & 1 & 1 & 1 & 1 & 0 & $4(11.8)$ & $6(17.6)$ & $20(58.8)$ \\
\hline$\chi^{2}$ & & & & & & & 4.338 & 3.939 & 0.195 \\
\hline P-value & & & & & & & 0.037 & 0.047 & 0.659 \\
\hline
\end{tabular}
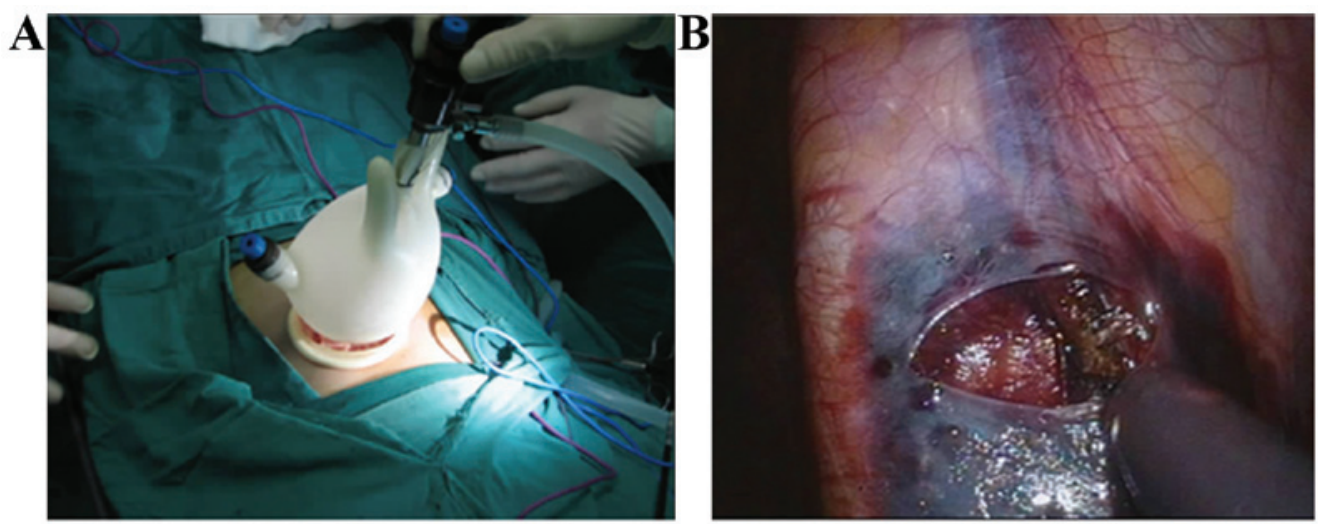

Figure 1. (A) Self-made single-port and multi-channel cannula and the establishment of pneumoperitoneum; (B) separation of spermatic vein and the coagulation of spermatic vein with ligasure.

becomes spasmodic and atrophic. It can be due to traction and stimulation which makes it difficult to distinguish the inner spermatic vein during the operation and causes missing ligation (10). Therefore, when we are separating and dealing with the spermatic cord we should distinguish and push the spermaduct away (which is the hardest tubular tissue in the spermatic cord) while cutting the cremasteric fascia off. iii) Occurrence of the venous obstructive lesion. Venous obstructive lesion usually occurs in the inferior vena, common iliac artery, internal iliac artery and peripheral vein after ligation of the inner spermatic vein which may result in the recurrence of VC (11). iv) Faulty ligation of inferior epigastric vein. The inferior epigastric vein is in the deep inguinal ring and is close to the spermatic vein and it runs through the inside of the spermatic vein, which may results in the faulty ligation of inferior epigastric vein. Use of high ligation may effectively avoid such faulty ligation. v) Ligation position is extremely low. Results obtained from a prior study showed $(12,13)$ that in cases that testicular vein is positioned lower, more branches of the vein are presented. Testicular vein branches below the height of $\mathrm{L}$ 5 are usually $1-5$. The occurrence rate of testicular vein may reach $72 \%$ when the branches of the testicular vein below the L 5 height are 2.

Advantages and disadvantages of TUSPLV. TUSPLV can establish pneumoperitoneum by a multi-channel canula and forms an operating space for flexible laparoscopy instrument. This can increase the rate of success for the operation (14). However, this operation requires special instruments with complicated structure, wide varieties and operational difficulties carry a high risk of causing damage (15). We were successful in completing this operation with minimal complications by the using a self-made single-port and multi-channel cannula. We used instruments such as cannulas, rubber rings and gloves that are all common surgical instruments. Using common and inexpensive materials makes the operation less complicated. We can also take advantage of the existing traditional laparoscopy instruments without any need to purchase expensive flexible instrument and endoscope (16).

There are a few factors that should be considered during the operation: i) Surgical instruments can be intersected after entering the abdominal cavity through the single-port cannula in the reverse direction of the multi-port laparoscope. Also, the instruments on the left hand are shown as on the right hand after they are placed in the body. Therefore, surgical team needs time to adapt to this situation (17); and ii) endoscope and surgical instruments enter the body from the same port and collision between them may be unavoidable and the use of traditional surgical instruments may cause more collision (18). We used high-definition endoscope and the collision between the endoscope and surgical instruments was reduced when the endoscope kept a far distance from the operation site during the operation (19). The cooperation between the endoscope operator and the doctor-in-charge is essential and can reduce the probability of collision among different instruments. In addition, the missing vein ligation and faulty ligation of arterial lymph-vessel may be avoided when we carry out the laparoscopic spermatic vein ligation. We should carefully 
observe the vein branches with endoscope and then cut the peritoneum with scissors to separate the vein. When separating the vein, the testicular artery should be watched closely to avoid any unwanted damage to this artery. By keeping the testicular artery intact, complications caused by faulty ligation and missing ligation resulting from blurred vision can be avoided (20).

Our results have shown that the time of operation and bleeding volume in the observation group reduced significantly. Moreover, the occurrence and recurrence rates of periprocedural complications decreased significantly. We concluded that TUSPLV is safe and effective in the treatment of recurrent $\mathrm{VC}$.

\section{References}

1. Esteves SC and Agarwal A: Afterword to varicocele and male infertility: current concepts and future perspectives. Asian J Androl 18: 319-322, 2016.

2. Pastuszak AW and Wang R: Varicocele and testicular function. Asian J Androl 17: 659-667, 2015.

3. Kim J, Shin JH, Yoon HK, Ko GY, Gwon DI, Kim EY and Sung KB: Persistent or recurrent varicocoele after failed varicoelectomy: outcome in patients treated using percutaneous transcatheter embolization. Clin Radiol 67: 359-365, 2012.

4. Kattan S: Incidence and pattern of varicocele recurrence after laparoscopic ligation of the internal spermatic vein with preservation of the testicular artery. Scand J Urol Nephrol 32: 335-340, 1998.

5. Kageyama Y, Horiuchi S, Yamada T, Kura N, Negishi T and Yoshida K: Postoperative hydrocele testis as a complication of high ligation of internal spermatic vein. Hinyokika Kiyo 34: 851-854, 1988 (In Japanese).

6. Lv JX, Wang LL, Wei XD, Zhang Z, Zheng TL, Huang YH, Zhou J, Xia F and Pu JX: Comparison of treatment outcomes of different spermatic vein ligation procedures in varicocele treatment. Am J Ther 12: 13-14, 2015.

7. Grober ED, Chan PT, Zini A and Goldstein M: Microsurgical treatment of persistent or recurrent varicocele. Fertil Steril 82: $718-722,2004$
8. Marsman JW: The aberrantly fed varicocele: frequency, venographic appearance, and results of transcatheter embolization. AJR Am J Roentgenol 164: 649-657, 1995.

9. Moon KH, Cho SJ, Kim KS, Park S and Park S: Recurrent varicoceles: causes and treatment using angiography and magnification assisted subinguinal varicocelectomy. Yonsei Med J 53: 723-728, 2012.

10. Choi WS and Kim SW: Current issues in varicocele management: a review. World J Mens Health 31: 12-20, 2013.

11. Rotker K and Sigman M: Recurrent varicocele. Asian J Androl 18: 229-233, 2016.

12. Chen SS: Predictive factors of successful redo varicocelectomy in infertile patients with recurrent varicocele. Andrologia 46: 738-743, 2014.

13. Shabana W, Teleb M, Dawod T, Elsayed E, Desoky E, Shahin A, Eladl M and Sorour W: Predictors of improvement in semen parameters after varicocelectomy for male subfertility: a prospective study. Can Urol Assoc J 9: E579-E582, 2015.

14. Canes D, Desai MM, Aron M, Haber GP, Goel RK, Stein RJ, Kaouk JH and Gill IS: Transumbilical single-port surgery: evolution and current status. Eur Urol 54: 1020-1029, 2008.

15. Kommu SS and Rané A: Devices for laparoendoscopic single-site surgery in urology. Expert Rev Med Devices 6: 95-103, 2009

16. Rane A, Rao P and Rao P: Clinical evaluation of a novel laparoscopic port (R-PORT ${ }^{\mathrm{TM}}$ ) in urology and evolution of the single laparoscopic port procedure (SLIPP) and one port umbilical surgery (OPUS). J Endourol 21: 22-23, 2007.

17. Sun YH, Wang LH, Yang B, Xu CL, Hou JG, Xiao L and Liu B: Single-port transumbilical laparoscopic nephrectomy: initial clinical experience of 3 cases. Zhonghua Wai Ke Za Zhi 47: 1709-1711, 2009 (In Chinese).

18. Kaouk JH and Palmer JS: Single-port laparoscopic surgery: initial experience in children for varicocelectomy. BJU Int 102: 97-99, 2008.

19. Kang DH, Lee JY, Chung JH, Jo JK, Lee SH, Ham WS, Cho KS, Lee KS, Kim TH and Lee SW: Laparoendoscopic single site varicocele ligation: comparison of testicular artery and lymphatic preservation versus complete testicular vessel ligation. J Urol 189: 243-249, 2013.

20. Fu B, Wang GX, Sun T, Cui SP, Cao RF, Feng L, Xi HB, Chen QK and Zhang X: Single-port transumbilical laparoscopic surgery in urology with report of 18 cases. J Clin Urol 24: 805-808, 2009. 